\title{
Ken(shin)do(es it): Exploring Anime Fandom as a Driving Motivation in Practicing Martial Arts Roehl Niño Bautista
}

Mass media has long been known for its capacity to influence and inspire its audience. Aside from being able to motivate viewers to consume a product and to participate in a real-world event, it can also spur them to engage in activities that are related to a television show's theme. In connection with this last point, this study explores the link between the Japanese manga, anime, and movie series and cultural product Rurouni Kenshin and the Filipinos' motivation in joining a kendo club. A survey of 50 Filipino kendoka or kendo practitioners, which covers questions regarding their exposure to the anime, movie, and/or manga versions of Rurouni Kenshin and their reasons in practicing the martial art, reveals the franchise's significant influence on them, together with other factors such as generic interest in Japanese culture, self-improvement, and other media product influences.

Keywords: Japanese media, kendo, martial arts, fandom, media influence, anime

"Japanese martial arts-like many such arts in East and Southeast Asia-partake of a serious artistic dimension-an explicitly aesthetic aspect-that makes them part and parcel of the Japanese cultural experience." (Ben-Ari, 2005, p. 333)

Between the late 1990s to the early 2000s, the animated version of Rurouni Kenshin (るろうに剣心 or Wandering Kenshin), also known as Samurai $X$ in some countries, aired on Philippine national television, first over ABS-CBN in Filipino and later over Studio 23 and AXN (cable) in English (Furuhashi, 1996). Based on the comic book of the same title, the series told the adventures of Kenshin Himura during Japan's Meiji era, a period of relative development in Japanese history following the Boshin War fought by the Tokugawa shogunate and the emperor's forces. Kenshin became a favorite figure amongst television viewers. With his trademark " $\mathrm{X}$ " scar on 
his cheek that marked him as a legendary swordsman, he wielded a reverseedged sword (sakabatou) as part of a vow to never kill again, atoning for the lives he claimed during his assassin days and instead choosing to dispose his opponents in a nonlethal manner.

Rurouni Kenshin (Furuhashi, 1996) came in during what one may call the golden era of anime on Philippine television, or simply Philippine Anime Era, when significant airtime was allotted to Japanese animation, with major television networks in the country importing big-name series from Japan (Bravo, 2006, 2012). Filipinos who frequently watched television from the late 1990s to early 2000s can most likely name more than a handful of anime that aired on the big networks. The most notable perhaps from GMA were Voltes V, Daimos, and Pokemon, which were shown every Friday night, while multiple Gundam series, Yuyu Hakusho, Flame of Recca, Hunter $x$ Hunter, and Dragon Ball Z, to name a few, enjoyed afternoon to evening airtimes. For ABS-CBN, the following titles were among the memorable ones broadcast in that era, aside from Rurouni Kenshin: Digimon, Zenki, Magic Knight Rayearth, B't X, Cardcaptor Sakura, and Evangelion. Years later in the early 2010s, some Filipinos who watched Rurouni Kenshin in their youth would join kendo clubs.

Kendo (剣道 or Way of the Sword), is a martial art based directly on swordsmanship practiced by the samurai or Japanese elite warriors, and it substitutes the lethal blade with bamboo swords to safely simulate fullcontact combat (Ben-ari, 2005; Donohue, 1990). This sporting tradition of kendo has already established its presence in various parts of the Philippines due to the country's long connection with Japanese culture. Most Philippine kendo clubs were formed after 2010. Given that Rurouni Kenshin aired between the late 1990s up to the early 2000s, and that its theme was swordsmanship that was similar to kendo practice, the anime may have exposed young viewers then to the existence of Japanese sword fighting and may have been responsible for planting the desire to study swordsmanship in them, so much so that they have become today's kendoka or kendo practitioners.

\section{Rurouni Kenshin Fame}

But is Rurouni Kenshin really popular in the Philippines?

On August 6, 2014, a horde of fans gathered at SM Megamall in Ortigas, a business district in Metro Manila, where actors of the Rurouni Kenshin live action trilogy appeared for the second movie's premiere (Bautista, 2014). Actors Takeru Satoh (Kenshin Himura), Emi Takei (Kaoru Kamiya), and Aoki Munetaka (Sanosuke Sagara) were joined by director Keishi Otomo as they took their time on the red carpet signing autographs for and 
interacting with the adulating crowd (Bautista, 2014). The cast's Manila visit was the "only premiere event of the movie (Kyoto Inferno) outside Japan" (Smith, 2013). Five days after officially opening on August 20, the movie made Philippine box office record for grossing P42.61 million-a clear measure of Rurouni Kenshin's fame in the country. A month later, it already hit the P79-million mark, which was almost double the numbers reached by the first movie's local run when it was shown in only one mall chain in 2012 (Sallan, 2014). The figures can be considered a feat for the live-action adaptation of an anime that became famous in the country more than a decade earlier. Rurouni Kenshin: Kyoto Inferno's record was the best among all the Japanese films that hit Philippine theaters, with PhilStar Online (Orosa, 2014) reporting the film achieving "All-Time Biggest Opening Weekend' for a Japanese film" (para. 1). What was not available, however, was data on other Japanese films that have been commercially released in the country. It is also important to note that the first Rurouni Kenshin movie was only shown in SM Cinemas, but the sequels were shown in more theaters, which can explain why Kyoto Inferno surpassed the first movie's figures. (Orosa, 2014)

There are many methods in which the Rurouni Kenshin fandom could be expressed, and the cast's visit was a witness to largescale fan participation. During the red carpet premiere, a fan cosplaying Munetaka's character Sanosuke Sagara had a fun and rowdy moment with the actor-shouting, fist bumping, and having photos taken together. Satoh, on the other hand, was quite formal upon meeting a female cosplaying Kenshin. Aside from accommodating many fans in costumes, the cast also autographed posters and DVDs (Bautista, 2014). For the cast's public press conference at the Glorietta Mall the next day, some fans came hours early, some hailing from as far as Davao and Pangasinan (Ong, 2014). It was a huge reception for a movie that required subtitles to be watched outside of Japan.

Beyond cosplaying and attending Rurouni Kenshin events, Filipino express their fandom by picking up a wooden sword and seeking an activity that is closest to the Japanese swordsmanship portrayed in the story. This study focuses on the latter activity and sets out to find answers to the question "How is Rurouni Kenshin an influence on the Filipino kendoka's decision to become a member of a kendo club?" But before exploring the kendo club members' motivations, here is some context on anime fandom in the Philippines.

\section{Notes on Fandom and their Activities in the Philippines}

Viewers who take a major liking for a certain anime series may express their fandom through various forms. Common modes of expression 
include writing fan fiction, sketching fan art, and cosplaying. Others help in distributing fansubs of a series (Agcaoili, 2011; Lee, 2011; Leonard, 2005) or scanlations of manga (Lee, 2009). Mizhelle Agcaoili (2011) noted the active participation of Filipino fans in international fansubbing communities. Fansubbers are defined as "fans who make Japanese media more accessible to a larger community sharing the same interest, by appending translated text onto the original video, for the mere purpose of pleasure" (Agcaoili, 2011, p. 4), undertaking meticulous post-processing of their acquired material either for profit or non-commercial purposes.

A strong fandom culture is also evident in the Philippines as seen in the existence of anime and cosplay conventions (Bravo, 2012), with one of its pioneers being the now-defunct Culture Crash Comics. Established in 2000, the publication featured multiple story series with an art style that "takes its cue from Japanese artists, or rather the popularized form of manga art" (Flores, 2004, p. 50). It also organized the First Philippine Comic Book and Anime Convention, also known as Culture Crash Convention or C3. Emil Flores, however, lamented that "the convention was more of an anime show where virtually no Filipino creators were involved" (p. 56) and "while it may be argued that anime is part of the Philippine popular culture, it was quite sad to see creators and creations of traditional komiks get virtually ignored amidst the din of cosplay (costume play) and J-pop (Japanese pop)" (p. 56). As for C3's contribution to the anime fan scene, arguably the most famous local cosplayer, Alodia Gosiengfiao, made her debut with her sister Ashley at one of its events ("Alodia Gosiengfiao and Ashley Gosiengfiao: Darlings of the Crowd," 2004).

\section{Captain Tsubasa: Anime as a Way into Sports}

In the "Media Effects" chapter of his book A First Look at Communication Theory, Emory Griffin (2012) noted the strength of television to "stir up feelings" (p. 355) under the Excitation Transfer Theory. The Social Learning Theory, on the other hand, "predicts [that] the use of force modeled on television today may erupt in antisocial behavior years later" (p. 356). These theories discuss the direct effect of media on a viewer: the former highlights how television affects mood and action, while the latter says that television plants seeds of influence that may manifest in a viewer's future action. The examples provided in Griffin's book lean toward the more negative effects of television, such as violence. But if you replace these effects with positive ones, the theories provide the appropriate framework for viewers who imitate nonviolent images presented in mass media. For athletes on television do motivate kids to pick up a ball and practice dribbling or kicking, and of 
course anime does inspire its fans beyond just writing and drawing fiction, dressing up, or helping distribute underground copies.

The fictional story of football prodigy Tsubasa Oozora, as chronicled in the manga and anime Captain Tsubasa, for example, is credited for having inspired numerous professional players in their youth, not just in Japan but in other countries such as Argentinian Lionel Messi of FC Barcelona and French legend Zinedine Zidane (Horcel, 2015; Veera, 2017). Spanish striker Fernando Torres cited the anime which aired in Spain as Oliver y Benji as an inspiration (Kent, 2012; “Torres: This is a World Cup," 2012). "I started playing football because of this, and because my brother forced me, and I loved the cartoon" (Kent, 2012, para. 6), he said. "I wanted to be Oliver, because he played out on the field and Benji was the goalkeeper. That was the first contact I had with Japan" (para. 6). Meanwhile, Italian international and World Cup winner Alessandro del Piero (2011) shared that he joined the Facebook campaign "to change your profile picture on social network for a cartoon of a hero of your childhood" (para. 1). His photo of choice was an artwork of Captain Tsubasa's creator, Yoichi Takahashi. He noted that in Italy, the series was known as Holly and Benji. In another trace of Captain Tsubasa's prominence outside Japan, FC Barcelona manager Luis Enrique said in a press conference that Messi does things he hasn't seen before even after seeing Oliver and Benji, who did things he thought was unthinkable (Llorens, 2014)

Takahashi created Captain Tsubasa in 1981, when "even 'World Cup' was an unfamiliar term" (Iwamoto, 2011, para. 9) in Japan. "I had to go around explaining in Captain Tsubasa that the World Cup is such and such an event, that it's the world's greatest tournament, held every four years" (para. 9) Takahashi said in an interview with Nippon.com. Iwamoto noted that since the manga's publication and eventual anime run, "Japanese soccer has made remarkable strides" (para. 10) and that Takahashi's creation is often credited as a vital variable. To this, the creator said:

I think it isn't so much the influence of Captain Tsubasa as it is the appeal of soccer itself that has led to the wide acceptance that the sport enjoys today. But I'm grateful that people say so, and it honestly pleases me to think that I may have been able to give a boost to Japanese soccer to some degree. (Iwamoto, 2011, para. 10)

The classic model of media effects generally asserts that television and other forms of media can influence its audience in varying degrees (Griffin, 2012). Media audience can be encouraged to purchase original show merchandise, from food-related and character-themed products to 
toys such as the case of masu komi gangu, which are mass media toys based mainly on manga and anime characters that started during the 1960s in Japan (Steinberg, 2012). Masu komi gangu buyers, according to Marc Steinberg, were able to expand the make-believe world of these anime characters, with owners inventing stories or creating fan fiction during play time with their toys, and basing their narrative on the characters represented by these toys. This product consumption paved the way for the growth of the Japanese toy industry, with masu komi gangu being marketed to older audiences who have more purchasing power than children (Steinberg, 2012).

Meanwhile, Bernadette Bravo (2012) identified consumption of Japanese cultural products such as toys, comics, and games as the precursor of organized gathering of consumers or conventions, where Philippine cosplay was widely believed to have been born. The existence of overlapping interest on Japanese cultural products were attributed to the "popularity and pervasiveness of anime in the Philippines" (p. 45) that occurred in the country from the late 1990s to early 2000s. Cosplay in the Philippines is an outcome of anime exposure, with the product being the act of imitating the mannerism and likeness of a preferred character (Bravo, 2012, 2016). But does imitation have to be as direct as nailing a hairstyle or outfit? Indirect imitation, that is, engaging in an activity that is close to or exactly the consumed media's theme, can also be seen as the effect of media exposure and, furthermore, the expression of adulation.

In the case of Captain Tsubasa, some of its audience transition from watching football animation on television to playing football in real life. The relationship is very direct: the theme is football, and the form of imitation expressed by some consumers is playing football. As for the case of Rurouni Kenshin, the form of imitation that is not cosplay is the practice of kendo, the closest practice of active swordsmanship as portrayed in the story.

\section{Motivating Martial Arts Practice and Kendo in the Philippines}

In his review of Hurst's Armed Martial Arts of Japan: Swordsmanship and Archery, Eyal Ben-Ari (2005) shared how the author noted the transition of swordsmanship and archery from their lethal forms and intentions to forms that are considerably aesthetically pleasing and more suitable for the changing times:

[Hurst's] thesis centers on the ways in which certain military training, which was no longer needed given the pacification of the country, led to the development and cultivation of new elements such as physical fitness, spiritual composure, and character development. (p. 333) 
Instead of classifying kendo (swordsmanship) and kyudo (archery) as martial arts, Hurst, as noted by Ben-Ari (2005), "prefers to talk about these martial arts as sporting traditions rather than as sports in the common Western definition of such endeavors" (p. 333). From training with the intention to kill with one swing, the focus of practicing swordsmanship shifted from "self-protection" to "self-perfection" (p. 333).

The challenge of swordsmanship in attaining the status of sport lay in its tendency to be lethal, due to the hazardous tradition of various schools in passing their secret techniques. Archery, with its practitioner-versus-target nature, as compared to swordsmanship's practitioner-versus-practitioner, successfully transitioned to a sport much earlier (Ben-ari, 2005). Through the development of bamboo swords and protective armor, full-contact swordsmanship could now be practiced through kendo. Cameron Hurst (as cited by Ben-ari, 2005) described how kendo "has made a revival in the post-war period and is now seen by its numerous practitioners as a form that combines competition, camaraderie, character development and the revitalization of traditional values" (p.333).

John Donohue (1990) studied various budo (literally "martial way") dojos in New York: kendo, aikido, and judo. In all dojos of the sporting traditions he observed, he noted the presence of the symbolic preservation of Japanese character and culture. According to him, there were three dominant themes: "(1) the importance of rank and hierarchy in human relations, (2) an emphasis on the corporate nature of social endeavor, (3) and the link between physical and spiritual development dojo" (p. 56). These themes are definitely also found in local dojos. The Manila Kendo Club, formed in the 1970s, was the first local dojo, but it was relatively low-key. Recent years saw the establishment of more clubs in the country: QC-based IGA Kendo Club in 2010, UP Kendo Club in 2011, Iloilo Kendo Club in 2013, and Davao Kendo Club in 2014. In November 2015, the establishment of Cebu Kendo Club was announced on the Philippine Kendo Community Facebook Group (Lardera Jr., 2015). In 2016, the United Kendo Federation of the Philippines was born (Inting, K., personal communication, September 10 2018).

\section{From Rurouni Kenshin Fan to Kendoka: Finding the Connection}

The basic framework that this study adopted is that of the general cluster media effects (Borah, 2016), wherein media consumption can influence the audience's mental state, psychology, and cultural awareness. This influence later on becomes motivation for the audience to perform an action related to what they have seen or experienced from the media (Griffin, 2012). Applying the framework to Rurouni Kenshin, this study posits that its 
anime, movie, and/or manga forms may drive a media consumer to mimic certain elements of the story.

This study employed quantitative survey research on the existing membership of IGA Kendo Club's two dojos in Arena, Quezon City and Dasmariñas Village, Makati. UP Kendo Club and Iloilo Kendo Club members also participated in the survey. Fifty kendoka or kendo practitioners from these clubs answered the questionnaire through links sent individually and posted in their club groups. Respondents were free to answer anonymously or to identify themselves. One of the key questions explored was whether the consumption of Rurouni Kenshin (anime, manga, and/or movie versions) stirred the desire in the respondents to join kendo clubs. Given that these clubs were formed in 2010 and that Rurouni Kenshin aired between the late 1990 s to the early 2000s, the anime may have planted the seed to study swordsmanship in these kendoka much earlier in their lives.

Interviews were also conducted with selected members who identified themselves in the survey as being exposed to Rurouni Kenshin and having it as one of their motivations; being exposed to Rurouni Kenshin and not having it as one of their motivations; being exposed to Rurouni Kenshin and having it as their only motivation; and not being exposed to Rurouni Kenshin at any point before and after their kendo membership. A large majority of the Filipino participants for this survey were in their twenties. The majority of Filipino respondents came from IGA Kendo Club Arena, the oldest of the four dojos surveyed. Two-thirds of the 50 respondents were male.

Below are some demographic information of participants in relation to their exposure and familiarization with Rurouni Kenshin:

Fig. 1. Fifty kendoka from different clubs and dojos answered the questionnaire though links sent individually and posted in their respective groups.

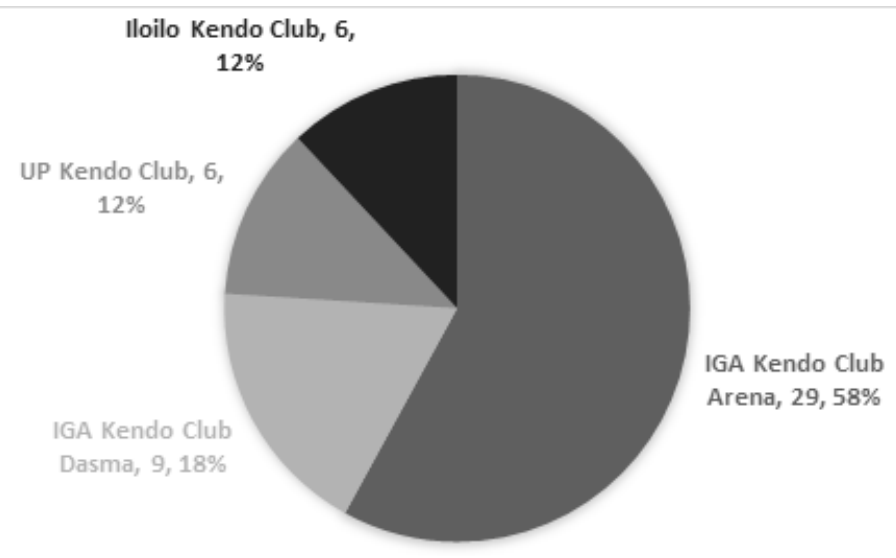


Fig. 2. Most of the kendoka respondents in the survey are between 21-30 years old.

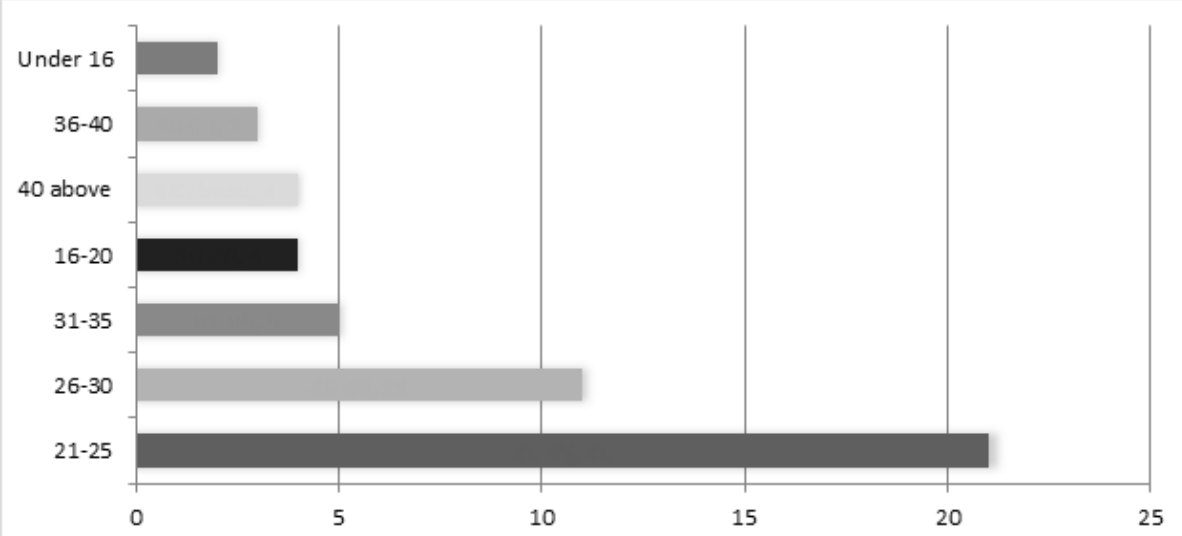

Most of the Filipino respondents of the survey said that they were exposed to Rurouni Kenshin. The movie and anime were the most common Rurouni Kenshin productions that most respondents were exposed to. One of the two respondents who said that they did not watch or read any Rurouni Kenshin material was 43 -year-old Florencio Sebastian III ${ }^{1}$ from IGA Kendo Club Arena. "While I appreciate Japanese culture, I am not attuned to the latest in fictional characters, anime or otherwise, unless those who are into it introduce these to me" (personal communication, December 5, 2015), he said.

Fig. 3. Only two respondents have no idea about Kenshin Himura, with almost all respondents answering yes to the question "Have you been exposed to Rurouni Kenshin?"

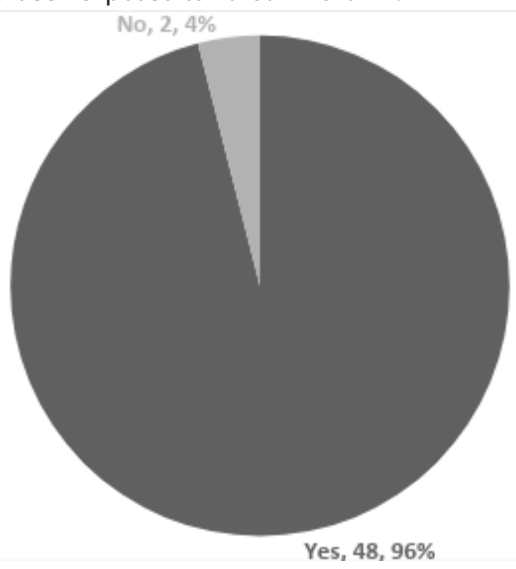

As for exposure to a combination of Rurouni Kenshin productions, the most common was exposure to all three forms by 20 respondents, together with another 20 being exposed to the anime and movie only. No respondent was exposed to manga alone, suggesting that the consumption of the manga version has always been in connection with the consumption of other forms 
of Rurouni Kenshin. From these findings, one can see that the most common form of exposure is from the animated and live-action versions of Rurouni Kenshin. The anime and the movie express movement, and these screen forms are much more visual than the static nature of the print manga.

Fig. 4. Rurouni Kenshin Media Exposure. Asked to pick which type of Rurouni Kenshin media have they encountered, responding kendoka picked the movie and anime versions the most.

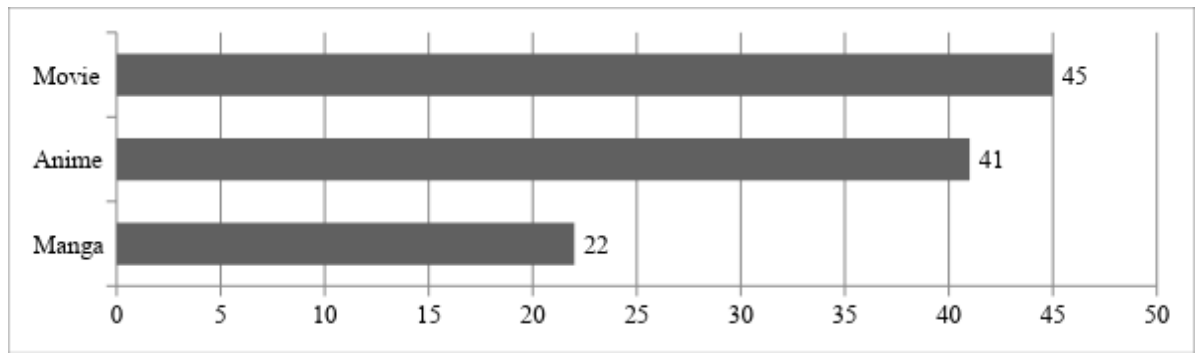

Rurouni Kenshin manga consumption is low among respondents. This researcher noted that chapters of the manga, although available in select comic and hobby shops, were expensive compared to today's prices of manga in local bookstores. ${ }^{2}$ The Rurouni Kenshin anime and movie were also more accessible to viewers, with the former made available through local television and the latter released in various cinemas nationwide. Thus, it is no surprise that they were the most common mediums of exposure. Of the respondents who had Rurouni Kenshin exposure, most of them said their first encounter with the series was before they started kendo. One of them was 23-year-old Jezreel Benliro from Iloilo Kendo Club. He first tried kendo in the middle of 2014. "I saw Rurouni Kenshin when I was around 12 years old. It was an afternoon television program when I was in elementary until high school" (J. Benliro, personal communication, December 4, 2015), he recalled. "I remember there was an encore run of it on Studio 23

Fig. 5. Rurouni Kenshin exposure combinations 48. Twenty of the respondents have consumed Rurouni Kenshin in all its forms (anime, movie, and manga), while another 20 skipped the print version.

\begin{tabular}{|l|c|c|}
\hline \multicolumn{1}{|c|}{ Rurouni Kenshin exposure combinations } \\
\hline
\end{tabular}


from $2-5 \mathrm{pm}$. I was really a fan so I watched all of its live action movies at cinemas" (personal communication, Month Day, 2015).

Fig. 6. Q: "When was your first exposure to Rurouni Kenshin?"90 percent of respondents already knew about Rurouni Kenshin before they joined Kendo.

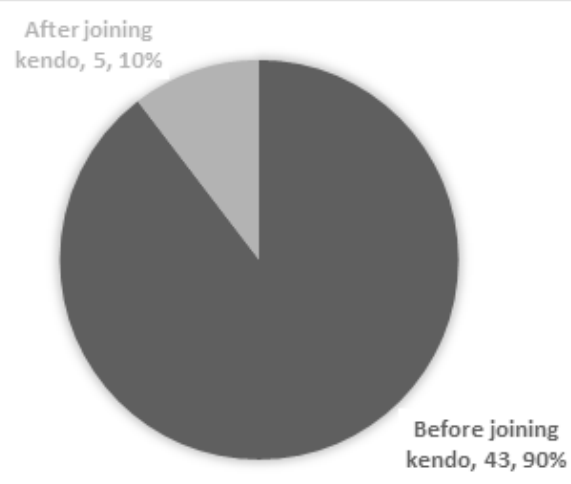

Fig. 7. Q: "Which statement fits you best?" More than half of the respondents credited Rurouni Kenshin as one of their many reasons in joining kendo. One respondent, however, picked the statement "Rurouni Kenshin was my ONLY inspiration in joining kendo.

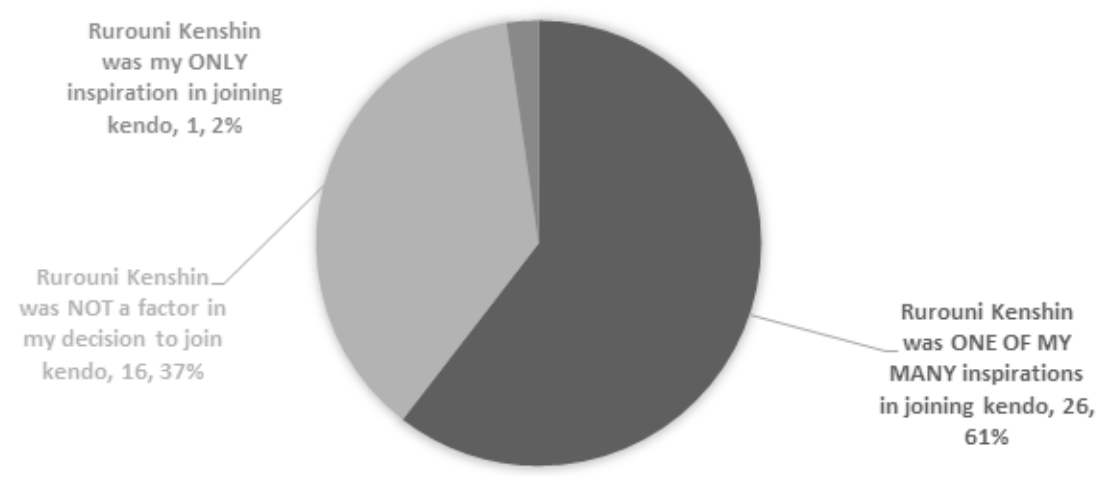

The 43 respondents who were exposed to Rurouni Kenshin prior to their kendo club membership were asked to pick the best statement that applied to them-Rurouni Kenshin was NOT a factor in my decision to join kendo, Rurouni Kenshin was NOT a factor in my decision to join kendo, or Rurouni Kenshin was my ONLY inspiration in joining kendo.

The majority of the respondents agreed with the statement that Rurouni Kenshin was one of their many inspirations in joining kendo, while only one picked the statement about Rurouni Kenshin being the only motivator for joining kendo. That lone respondent was Meryl Louise Brown, a 21-year-old kendoka from UP Kendo Club. In the survey, Brown (personal communication, December 4, 2015) also indicated that she has consumed 
all forms of Rurouni Kenshin: anime, movie, and manga. "[Rurouni Kenshin] had been my only motivation because honestly as a child I [was] not inclined to sports or any form of martial arts," she said. "Just then when I watched Rurouni Kenshin that it gave me the idea that I can perhaps do kendo since it is a semi-contact activity."

Brown found a Rurouni Kenshin and kendo connection "through episodes where characters are seen to practice and train in the dojo, especially at Kamiya Dojo" (personal communication, December 4, 2015) which was inherited and headed by the character Kaoru Kamiya. The dojo was an important setting at the start of all versions of the series, and was considered as the home of Kenshin Himura. Episodes, scenes, and chapters featuring the school showed Kaoru Kamiya practicing with a bokken (wooden sword) while her student Yahiko Myojin used a shinai (bamboo sword) in drills.

I have been fond of its rich historical premise first of all. It was like learning a very thorough history of the Meiji restoration period in a show that's also meant for entertainment. . . . Next was the battle techniques incorporated in each of the episodes, be it that of the protagonist or of the villain. (M. L. Brown, personal communication, December 4, 2015)

While Brown indicated that the series was her sole motivation in practicing kendo, other Filipino kendoka agreed with the statement that Rurouni Kenshin was just one of their many motivations. One of them was 26-year-old Jomar Paul Romero (personal communication, December 6, 2015), who had trained with IGA Kendo Club Arena since he was 21 years old before recently leaving for Japan to study. "Rurouni Kenshin added to my fascination of Japanese culture and martial arts," he said. "As I watch the anime, I imagine myself holding a katana and becoming a samurai. Since I was fascinated, I tried to look for any kendo dojo here in the Philippines until someone recommended me to join IGA Ken." Romero has a nidan rank and also practiced fencing as a student at UP Diliman.

For Romero (personal communication, December 6, 2015), who "fell in love with kendo since the first time I saw a shinai and was able to hold on to it," one can see the connection between Rurouni Kenshin and kendo if you "take away the flashy moves of Kenshin" through kenjutsu. "Kenjutsu is the father of Kendo, so to speak," he said. "Kendo was developed during the peaceful times of the Edo period as a mean to practice the practical aspects of kenjutsu, at the same time develop their spirit." This conforms to the development of kendo as mentioned by Ben-Ari (2005). 
Romero and Brown were part of the majority of respondents who were motivated in different ways by Rurouni Kenshin to join kendo. Almost three out of four of these respondents were in the 21-to-30-year-old age group. Benliro, however, was not part of that motivated group. For him, Rurouni Kenshin was not a factor in his decision to join a kendo club. "Kendo is a different thing. All I know about kendo before I started is that it was a sport or rather a martial art that was born out of the samurais" (Benliro, personal communication, December 4, 2015), he said. "I'm not an athletic person. I was a fresh employee at a far-away place and I wanted to start and do new things."

Fig. 8. Age Groups of Rurouni Kenshin-motivated Filipino Kendoka. Rurouni Kenshin-motivated kendoka are mostly between $21-30$ years old.

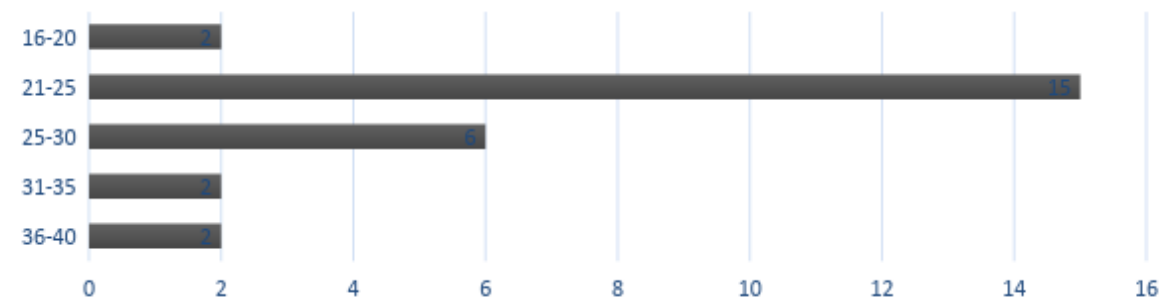

Figures 9 to 13 present the level of agreement of the respondents to given statements that provide a picture of their level of fannishness towards Rurouni Kenshin. The first statement is regarding the swordsmanship school called Hiten Mutsurugi of which Kenshin Himura was an expert. Hiten Mitsurugi is the technique practiced by Kenshin Himura throughout the series. Loosely translated as "Flying God Sword Technique," it is an integral part of the story, with the main character using its lethal nature with a nonlethal sword. The majority of respondents said that they were familiar with the fictional style.

The statements in Figures 10 and 11 check for instances of imitation that the exposed viewer expressed in relation to Rurouni Kenshin. While more kendoka emulated many of the Kenshin Himura techniques with either a tangible sword alternative or an imagined one, the number of kendoka who affirmed their act of imitation was nearly the same. Opinion was split among respondents when it came to imitating sword techniques using a sword substitute (Figure 10), but there were slightly more respondents who disagreed when it came to imitating Kenshin while holding nothing in their hands.

Imitating moves in Rurouni Kenshin was also common in all three respondents who were further interviewed. Brown and Romero strongly agreed with the statements "I have pretended doing one of Kenshin Himura's techniques using an umbrella / a broom /non-sword instruments" 
Fig. 9. 33 respondents agree with the statement "I know what Hiten Mitsurugi means"

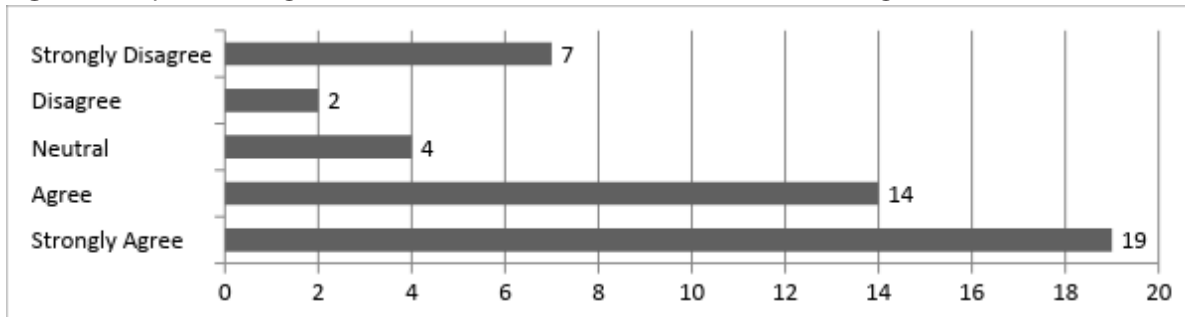

Fig. 10. There is a split among respondents in agreeing with the statement "I have pretended doing one of Kenshin Himura's techniques using an umbrella / a broom /non-sword instruments."

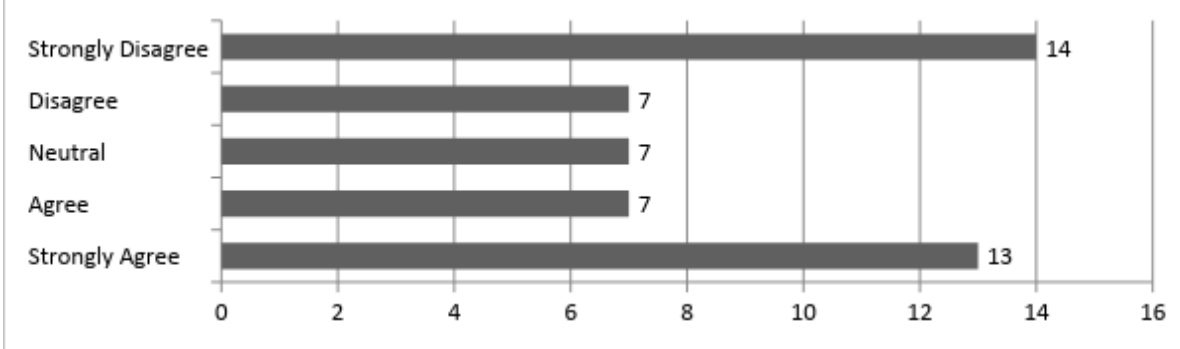

Fig. 11. The strong disagreement with the statement "I have pretended doing one of Kenshin Himura's techniques with an imaginary sword" is high among respondents, but total general agreement of twenty does not fall behind.

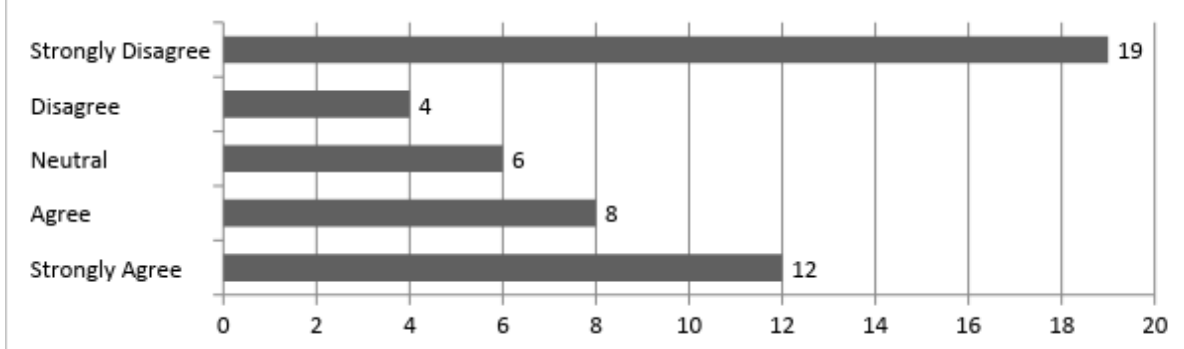

and "I have pretended doing one of Kenshin Himura's techniques with an imaginary sword." As for Benliro (personal communication, December 4, 2015), although he said Rurouni Kenshin's influence on him was "a thing of the past" and he was way past "the age when I copy their flashy sword techniques," he admitted that "I still do it with my shinai or bokken whenever no one's around."

Meanwhile, agreement with negatively-phrased statements "I DON'T want to be identified as a Rurouni Kenshin fan" and "I DON'T want Rurouni Kenshin-related merchandise" show that while almost twenty four or half of the respondents were fine with being identified as a Rurouni Kenshin fan, a considerable number of them were on the fence regarding the idea. 
A similar pattern appeared for the statement regarding acquiring Rurouni Kenshin-related merchandise, but with less neutral respondents.

Fig. 12. Seventeen respondents are on the fence regarding the statement, "I DON'T want to be identified as a Rurouni Kenshin fan," the highest rate of indecision in this survey.

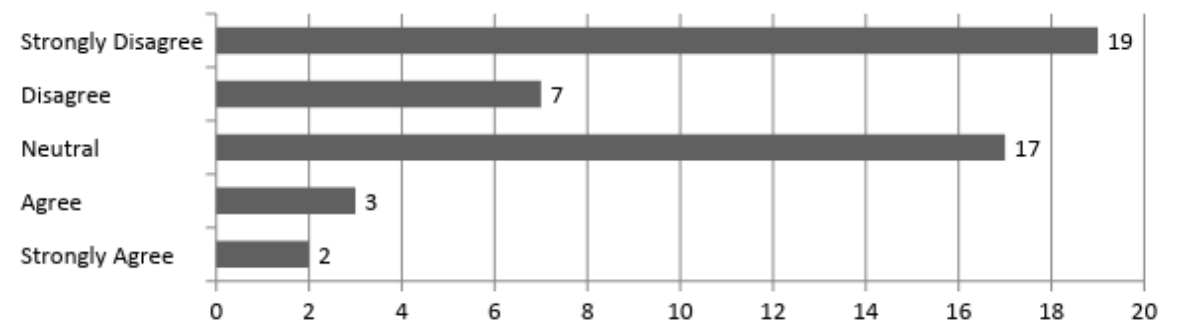

Fig. 13. Ten respondents are on the fence regarding the statement "I DON'T want Rurouni Kenshinrelated merchandise." The second-highest rate of indecision in this survey.

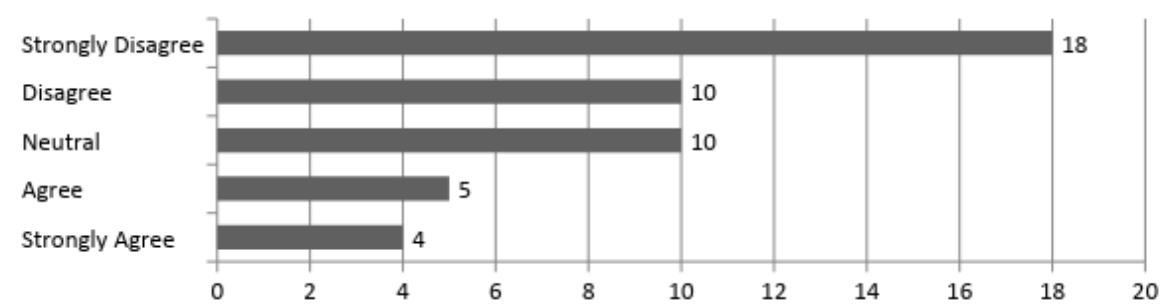

All respondents, including those who were not exposed to Rurouni Kenshin and excluding one who indicated Rurouni Kenshin as the only kendo motivator, were then asked to identify their top motivator from a list of statements (See Table 1). Majority chose statements that were related to their interest in Japan (Japanese sporting tradition, Japanese culture, and kendo). Nobody picked interaction with friends as their top kendo membership motivator.

Table 1. Other motivators in entering kendo Interest in armed Japanese sporting tradition, generic interest in kendo, and generic interest in Japanese culture topped respondents' top motivations, aside from Rurouni Kenshin, in joining kendo.

\begin{tabular}{|l|c|}
\hline \multicolumn{1}{|c|}{ Statement closest to actual top motivator } & $\begin{array}{c}\text { Kendoka who } \\
\text { chose statement }\end{array}$ \\
\hline Interest in armed Japanese sporting tradition & 9 \\
\hline Generic interest in kendo & 9 \\
\hline Generic interest in Japanese culture & 8 \\
\hline Watching other anime & 6 \\
\hline Desire to be fit & 4 \\
\hline Influenced by friend/s who is/are practicing/interested in kendo & 3 \\
\hline Desire to learn Japanese sporting tradition & 3 \\
\hline
\end{tabular}




\begin{tabular}{|l|l|}
\hline Desire to be more disciplined & 3 \\
\hline $\begin{array}{l}\text { Motivated by family member who is practicing/interested in } \\
\text { kendo }\end{array}$ & 2 \\
\hline Watching samurai movies & 2 \\
\hline Rurouni Kenshin was the ONLY motivator & 1 \\
\hline Interacting with Japanese friends & 0 \\
\hline Interacting with friends interested in Japanese culture & 0 \\
\hline
\end{tabular}

Using the same set of statements, all respondents were asked to pick all that were close to their actual motivators in joining kendo. Statements that included a "generic interest" in all things Japanese were the top choices, followed by armed influences (samurai movies, armed sporting tradition interest), media (anime and samurai movies as well) and self-improvement ("desire to be more disciplined" and "desire to be fit.").

The four respondents, Sebastian, Benliro, Brown, and Romero who were further interviewed also stressed the importance of personal development in their practice of kendo. "I was motivated to continue and practice kendo

Fig. 14. Common Kendo Membership Motivators Asked to pick all motivators that apply to them, thirty eight respondents included "Generic interest in Japanese culture."

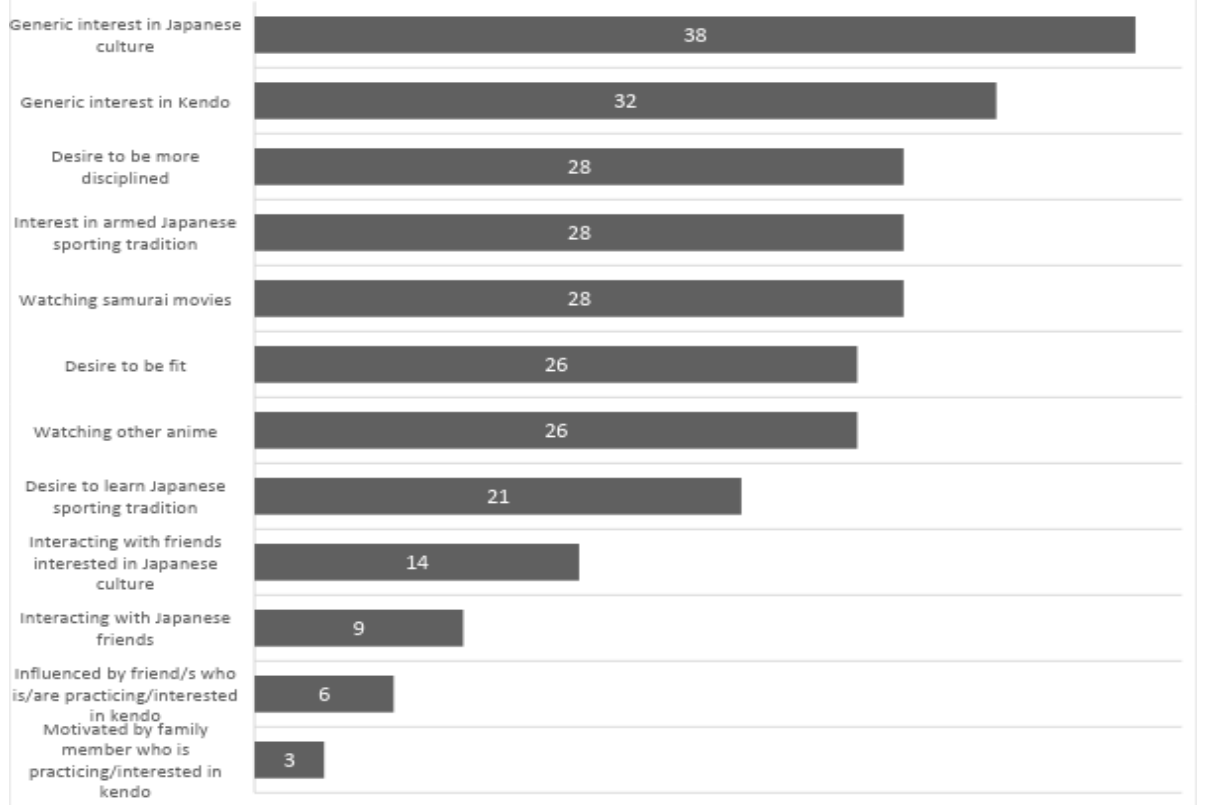


because it teaches discipline, patience, humility and respect. It's good for my health, both physical and mental" said Benliro (personal communication, December 4, 2015). "I found friends whom I could share my hobby and passion, who support me and help me do better in it. I think kendo fits my personality well" (personal communication, December 4, 2015), he added. Romero (personal communication, December 6, 2015) also continued kendo as a form of self-improvement, mentioning humility, discipline, respect, and mental health as important factors.

What drives me to continue kendo is my never-ending pursuit of strength and excellence. I always want to challenge myself, to break my limitations, to go beyond what I have imagined, and kendo provides me these things. Kendo is my refuge when I feel down, Kendo serves as the healer of my sanity. Kendo molds me into a person that I want to become. (Romero, personal communication, December 6, 2015)

For Brown (personal communication, December 4, 2015), she's motivated to continue kendo because "I felt physically better than before when I had not practiced any sport on a routine." Sebastian (personal communication, December 5, 2015), meanwhile, simply felt that kendo was for him: "I think that there is a sport for each person. In my case, I believe it is kendo." He also said that he loved kendo so much that it made him purchase an expensive bogu (armor) set. "I know that basketball, volleyball, weight training, and golf are not for me. I get bored. Tried it. Didn't last."

\section{Rurouni Kenshin as Kendo Membership Motivator: Conclusion}

Beyond the quick-paced action in Rurouni Kenshin that earned muchdeserved praise is the fact that despite being fictional, the movie is, in its all iterations, a cultural product. It is a comic book, an animation, a liveaction movie, with official merchandise available for fans to purchase in the form of toys, stationary, and clothing. It is an inspiration for cosplayers who join conventions. Moreover, nothing else but Rurouni Kenshin could have brought the huge crowd to Glorietta and SM Megamall last 2014 to cheer and scream for Kenshin Himura actor Takeru Satoh.

But consumption of a Japanese cultural product is not confined to consumption of goods, nor is it limited to interest in only one type of product. In the case of the Philippines, anime exposure is a motivation for some to learn the Japanese language, and an overlap of interests in Japaneserelated products has given birth to communities that cultivate interest in Japanese culture (Bravo, 2012). Therefore, Japanese media products are not 
just productions. They have grown to become ambassadors of the Japanese brand ("Pop-Culture Diplomacy," 2017; Prough, 2010).

The expression of Japanese fandom in the Philippines has always been a mix in perception and practice. Expression, of course, leads from one related interest to another. Bravo (2012) mentioned a case study that showed how interest in Japanese history was sparked by the animated story of Kenshin Himura. This case study, and other interviewees of Bravo (2012), started off as anime fans before studying the language. This researcher also notes the private or silent nature of local Japanese fandom groups as compared to Korean fandom groups. The latter enjoy a huge number of public activities, mostly anchored on music appreciation, while the former's bulk of activities revolves around those related to anime, such as conventions. Japanese songs, though not as widespread as Korean music, do resonate with Filipino viewers thanks to years of exposure to anime, and have since inspired explorations beyond the opening and closing themes of animated series toward listening to other Japanese music genres, creating local fan groups that are as dedicated but not as "public" as their Korean counterparts.

As a cultural product, Rurouni Kenshin can plant seeds of motivation that may sprout into different forms of inspired action towards appreciating Japanese culture in one way or another. As Satoh said through a translator during his visit:

Action movies have one language. Anyone can appreciate it. Other than that, us being Japanese and us creating a Japanese film, we are able to show the delicate intricacies of Japanese culture, the tradition, the way we do things in that era. We were really putting that in mind. We want people to understand and appreciate that part that is distinctively Japanese. ('Rurouni Kenshin' stars Manila press conference," 2013)

Rurouni Kenshin appears to be a significant motivator for the respondents in entering kendo, while general interest in Japanese culture and self-improvement were the top additional motivators. The trend for this sample was that younger kendoka in their twenties had been positively motivated by Rurouni Kenshin. While the series was rarely the sole motivator for participants, it was frequently one of their motivating factors in joining kendo. A number of respondents also admitted to playfully imitating Kenshin Himura. However those who were happy to be identified as Rurouni Kenshin fans were just as many as those who were undecided on the matter. Those who were further interviewed also saw connections between the 
series and kendo, through their common history of swordsmanship and the prevailing martial arts theme of the story.

These findings provide a positive perspective for the umbrella of media effects theories that focus on violence motivated by media exposure. In this case, kendo membership is a positive media effect of Rurouni Kenshin. For further improvement of this study, this researcher suggests a bigger survey sample from all existing clubs in the Philippines in order to produce more generalizable findings. Focus group discussions might also provide deeper insight regarding the motivations of Filipino kendoka in entering the sporting tradition. While this study inquired on kendo membership motivations through Rurouni Kenshin, other motivators could also be focused on, such as specific personal targets, or the aspect of interest in Japanese culture. 


\section{References}

Agcaoili, M. (2011). Hybrid identities: Filipino fansubbers. Asian Studies Journal, 47, 1-28. Retrieved from https://asj.upd.edu.ph/mediabox/archive/ASJ-47-2011/agcaoili.pdf.

Alodia Gosiengfiao and Ashley Gosiengfiao: Darlings of the Crowd. (2004). Culture Crash Comics Issue 14 Special $2^{\text {nd }}$ Comicbook, 10-13. Marikina City: Culture Crash Comics and J.C. Palabay Ent., Inc.

Bautista, R. N. (2014, August 7). Samurai ecstatic: 'Rurouni Kenshin' stars have a blast on the red carpet. GMA News Online. Retrieved from http://www.gmanetwork.com/news/story/ 373775/lifestyle/ samurai-ecstatic-rurouni-kenshin-stars-have-a-blast-on-the-red-carpet.

Ben-Ari, E. (2005). Militarism, martial arts, and aesthetics in Japan. Reviews in anthropology 34, p. 331-341

Borah, P. (2016, January). Media effects theory. Retrieved from https://www.researchgate.net/ publication/314119579/download.

Bravo, B. (2006). The influx of Japanese animation in the Philippines and Philippine-Japan cultural relations (Graduate thesis). University of the Philippines, Diliman Asian Center.

Bravo, B. (2012). Japanese cultural influence in the Philippine through anime's popularity and pervasiveness (Doctoral dissertation). Waseda University, Tokyo, Japan.

del Piero, A. (2011, November 17). Captain Tsubasa. Retrieved from http://en.alessandrodelpiero.com/ news/captain-tsubasa_228.html.

Donohue, J. (1990). Training halls of the Japanese martial tradition: A symbolic analysis of budo dojo in New York. Anthropos Institut, 55-63. Retrieved from http://www.jstor.org/stable/40462114 .

Flores, E. (2004). Comics crash: Filipino komiks and the quest for cultural legitimacy. Journal of English Studies and Comparative Literature, 7(1), 47-58. Retrieved from http://journals.upd.edu.ph/index. php/jescl/article/view/2530.

Furuhashi, K. (Director). (1996). Rurouni Kenshin [Television series]. Tokyo, Japan: Fuji TV.

Griffin, E. (2012). A first look at communication theory (8th ed.). New York: McGraw-Hill.

Horcel, T. (2015). Dreaming of glory: How Captain Tsubasa inspired a generation. Eifsoccer.com. Retrieved from http://www.eifsoccer.com/leagues/international/captain-tsubasa/.

Iwamoto, Y. (2011, October 18). A soccer hero adored around the world: An interview with Captain Tsubasa creator Takahashi Yōichi. Retrieved from http://www.nippon.com/en/views/b00103/?pnum=1.

Kent, D. (2012, December 10). Forget Pele, Maradona and Beckenbauer, meet the inspiration behind Torres' career...Japanese cartoon Captain Tsubasa. Dailymail.co.uk. Retrieved from https://www. dailymail.co.uk/sport/football/article-2245925/Fernando-Torres-I-took-football-Captain-Tsubasa. html.

Lardera Jr., J. T. (2015, November 12). In Facebook [Group page]. Retrieved from https://www.facebook. com/groups/philippinekendo/permalink/895149747205256/.

Lee, H. K. (2009, November). Between fan culture and copyright infringement: Manga scanlation. Media, Culture \& Society, 1011-1022. Retrieved from http://mcs.sagepub.com/content/31/6/1011.citation.

Lee, H. K. (2011, November). Participatory media fandom: A case study of anime fansubbing. Media, Culture \& Society, 1131-1147. Retrieved from http://mcs.sagepub.com/ content/33/8/1131.full. pdf+html. 
Leonard, S. (2005, September). Progress against the law: Anime and fandom, with the key to the globalization of culture. International Journal of Cultural Studies, 8, 281-305. Retrieved from http:// ics.sagepub.com/content/8/3/281.abstract.

Llorens, M. (2014, September 13). Luis Enrique: "Messi hace cosas que no vi ni en Oliver y Benji". futbol. as.com. Retrieved from http://futbol.as.com/futbol/2014/09/13/ primera/1410627765_915036. html.

Ong, W. (2014, August 7). WATCH: 'Rurouni Kenshin' stars, director delight fans at public presscon. Rappler. Retrieved from http://www.rappler.com/entertainment/movies/65587-video-rurounikenshin-kyoto-inferno-takeru-satoh-press-conference.

Orosa, R. (2014, August 25). 'Rurouni Kenshin: Kyoto Inferno' tops Philippine box office. Philstar Online. Retrieved from https://www.philstar.com/entertainment/movies/2014/08/25/1361617/rurounikenshin-kyoto-inferno-tops-philippine-box-office.

Pop-Culture Diplomacy. (2017, March 8): Retrieved from http://www.mofa.go.jp/policy/culture/ exchange/pop/index.html.

Prough, J. (2010). Marketing Japan: Manga as Japan's new ambassador. ASIANetwork Exchange, 54-68.

Rappler. (2014, August 7). 'Rurouni Kenshin' stars Manila press conference [Video File]. Retrieved from https://www.youtube.com/watch?v=hjL7jUfEE7Q.

Sallan, E. (2014, September 17). Box office success of 'Kyoto Inferno' sets up finale of 'Rurouni Kenshin' trilogy. Interaksyon.com. Retrieved from https//web.archive.org/web/20141227194714/http:// www.interaksyon.com/entertainment/box-office-success-of-kyoto-inferno-sets-up-finale-ofrurouni-kenshin-trilogy/.

Smith, C. (2013, August 6). In photos: Stars of 'Rurouni Kenshin' in Manila red carpet premiere. Philstar. com. Retrieved from http://www.philstar.com/entertainment/2014/08/06/1354715/photos-starsrurouni-kenshin-manila-red-carpet-premiere

Steinberg, M. (2012). Anime's media mix: Franchising toys and characters in Japan. Minneapolis: University of Minnesota Press.

Torres: This is a World Cup (2012, December 10). Retrieved from https://web.archive.org/ web/20130126170255/http://www.chelseafc.com/news-article/article/3005937/title/torres-thisis-a-world-cup.

Veera, S. (2012). FIFA U-17 World Cup: How a Japanese cartoon hero inspired legions of football players around the world. Indianexpress.com. Retrieved from https://indianexpress.com/article/sports/ football-fifa-u17-world-cup/how-a-japanese-anime-series-inspired-legions-of-football-playersaround-the-world-captain-tsubasa-japan-u-17-ronaldinho-fernando-torres-4885965/. 


\section{Notes}

${ }^{1}$ All interviewees granted permission to be named in this paper.

${ }^{2}$ This researcher has only owned one copy of the manga, worth around Php400 in the early 2000s, which was expensive at the time. Scanlations of Rurouni Kenshin are also rare, given that the series is pretty old and that the explosion of scanlations happened a long time after the manga had been published.

ROEHL NIÑO BAUTISTA is an MA Asian Studies student majoring in Northeast Asia and specializing in Japan at the University of the Philippines Diliman Asian Center. He is also a lecturer at the College of Mass Communication. His research interests include new media and popular culture, approaching area studies from a media perspective. (corresponding author: rabautista3@up.edu.ph ) 